\title{
Reflexões sobre a Dimensão Semiótica da Análise de Balanços: Uma contribuição à otimização de decisões de crédito
}

\author{
Reflections about the Semiotics Dimension in the Balance Sheet Analysis: A \\ contribution for the improvement of credit decisions
}

\author{
José Maria Dias Filho \\ zemariadias@uol.com.br \\ UFBA
}

\author{
Masayuki Nakagawa \\ nakagawa@usp.br \\ USP
}

\begin{abstract}
Resumo
Partindo do princípio de que a análise de balanços necessária à otimização de decisões de crédito não pode se limitar à simples extração de índices dos relatórios contábeis, este artigo procura demonstrar em que medida a teoria semiótica pode contribuir para a formulação de diagnósticos mais qualificados sobre a situação econômico-financeira das entidades. Entendese que, num processo de intermediação financeira, o analista deve procurar desvendar o verdadeiro significado dos números, ler nas entrelinhas e, principalmente, fazer os questionamentos mais relevantes. Deve, enfim, olhar para as demonstrações contábeis e procurar enxergar nelas a essência dos eventos econômicos que buscam representar. Isso implicar analisar as informações contábeis sob os aspectos sintático, semântico e pragmático. Como a Semiótica estuda todas as linguagens sob tais dimensões e considerando ser a Contabilidade uma espécie de linguagem, sugere-se que o conhecimento semiótico pode contribuir para aprimorar procedimentos de análise de balanços.
\end{abstract}

Palavras-chave: Análise de balanço, semiótica, decisões de crédito, linguagem contábil.

\begin{abstract}
Assuming that the balance sheet analysis to optimize credit decisions can not be limited to the simple extraction of financial rates of reporting, this article seeks to demonstrate the extent to which semiotics theory can contribute in the formulation of more qualified diagnoses about the economic and financial situation of entities. It has been understood that, in the financial intermediation process, the analyst should seek to uncover the true meaning of numbers, read between the lines and especially make the most relevant questions. It should finally look at the financial statements and seek to see in them the essence of economic events that seek to represent. This involves analyzing the financial information under syntactic, semantic and pragmatic aspects. Whereas Semiotics studies all languages under such dimensions and considering the Accounting as a kind of language, it is suggested that the knowledge of semiotic can contribute to enhance procedures of balance sheet analysis.
\end{abstract}

Keywords: Balance Analysis, Semiotics, Credit Decisions, Accounting Language.

Artigo recebido em: 28.02.2012; Aceito em: 23.03.2012

\section{CARACTERIZAÇÃo DO PROBLEMA}

Em geral, considera-se que a atividade de intermediação financeira busca na Análise de Balanços um instrumento de proteção para todos os elementos que dela participam: depositantes, tomadores de crédito e intermediários. Os depositantes estão interessados em 
informações que lhes permitam selecionar a instituição financeira com que poderão transacionar; os tomadores de crédito, por sua vez, também buscam apoio em informações de natureza contábil para avaliar custos de negociação, contratação e quitação dos empréstimos; e as instituições financeiras, na condição de intermediárias, também desejam encontrar nas informações contábeis meios de dimensionar riscos, monitorar custos, selecionar tomadores, avaliar projetos etc.

Diante disso, importa saber se a metodologia tradicional de Análise de Balanços proporciona as informações necessárias para se realizar tais atividades com segurança e ao menor custo possível. Afinal de contas, o sucesso da intermediação financeira depende do êxito de diversas atividades tais como seleção de clientes que apresentem potencial para honrar seus compromissos, identificação de projetos socialmente rentáveis, dimensionamento da capacidade de pagamento, avaliação de processos produtivos, estimativas de riscos etc.

Tudo isso nos leva ao entendimento de que a tarefa de analisar balanços não pode se limitar à simples manipulação de fórmulas, objetivando demonstrar oscilações de quocientes ou de números absolutos. Como bem salienta Schrichel (1999), analisar um balanço é algo muito mais desafiador, intrigante e estimulante. Em suas palavras, é preciso saber identificar o significado dos números, ler nas entrelinhas e, sobretudo, saber fazer as indagações mais contundentes.

Seguindo o mesmo raciocínio, pode-se afirmar que, no processo de análise de crédito, não serão apenas algumas fórmulas e quocientes que poderão oferecer respostas aos questionamentos mais relevantes. Mais do que classificar contas e gerar índices, o analista deve auscultar os números e procurar interpretá-los às luz das regras sob as quais foram produzidos. De modo mais abrangente, diríamos que é preciso compreender a linguagem contábil em sua essência, buscando conhecer os eventos econômicos que ela pretende revelar. Considerando que a Semiótica, como ciência de todas as linguagens, fornece recursos metodológicos para facilitar a compreensão dos fenômenos que tocam a consciência humana, inclusive os de natureza econômica, o presente artigo se propõe a responder à seguinte questão: em termos práticos, que contribuições a Teoria Semiótica pode oferecer para melhorar a qualidade da análise de balanços utilizada em decisões de crédito?

À esta altura, é possível que o leitor seja tomado por certa perplexidade e passe a nos questionar sobre o tipo de relação que existe entre Contabilidade e Semiótica. Dada a exiguidade de trabalhos dedicados a este tema no Brasil, não só compreendemos tal surpresa mas também sentimo-nos no dever de demonstrar que de fato existe uma forte relação entre os referidos ramos do conhecimento humano. O entendimento desta relação é condição fundamental para compreendermos a contribuição que a Semiótica pode oferecer à Análise de Balanços no processo de avaliação de riscos de crédito. Por isso, nas duas próximas seções, visitaremos alguns autores que poderão nos ajudar a cumprir esse desiderato.

\section{A CONTABILIDADE COMO LINGUAGEM DE NEGÓCIOS}

Considerando que a Semiótica é geralmente definida como a ciência que se dedica ao estudo de todas as linguagens, o primeiro passo para se compreender a relação que existe entre esse ramo do conhecimento e a Contabilidade é conceber esta última disciplina como uma espécie de linguagem. Para tanto, vamos verificar se a Teoria da Contabilidade oferece suporte a esse entendimento.

Hendriksen e Breda (1992, p. 28) nos ensinam que uma das classificações das teorias contábeis se apoia na noção de que a Contabilidade é uma linguagem e que essa disciplina tem sido considerada por muitos como a linguagem dos negócios. Esse autor acrescenta que 
as seguintes perguntas podem ser formuladas a respeito de uma linguagem e das palavras e frases que a compõem:

a) que efeito terão as palavras sobre os ouvintes?

b) que significado terão essas palavras, se houver algum?

c) as palavras fazem sentido lógico?

No mesmo trabalho, Hendriksen e Breda explicam que as respostas a cada uma das referidas questões formam parte do estudo de uma linguagem, que são: a pragmática, estudo do efeito da linguagem; a semântica, estudo do significado da linguagem; e a sintaxe, estudo da lógica ou gramática da linguagem.

Destacando o aspecto semântico da evidenciação contábil, Hendriksen e Breda alertam que $o s$ números e as classificações contábeis variam no tocante à interpretação que pode ser dada pelo leitor de relatórios contábeis. Além disso, esse autor enfatiza que a despeito dos esforços do Financial Accounting Standards Board - FASB, e por mais surpreendente que esse fato possa parecer para os iniciantes e o público em geral, é certo que muitos conceitos contábeis ainda não possuem conteúdo semântico.

Horngren (1974), por sua vez, concebe a Contabilidade como um tipo de linguagem que tem vocabulário especialmente direcionado a transmitir a história financeira das organizações. Esse autor afirma que, para entender os relatórios contábeis, o usuário deve dominar os fundamentos dessa linguagem. Destaca-se que esta é uma condição básica para que a informação contábil possa contribuir para melhorar a qualidade das decisões econômicofinanceiras.

Ijiri (1975, p. 14) também visualiza a Contabilidade como uma linguagem de negócios e considera que ela tem muito em comum com outros tipos de linguagem. Para esse autor, assim como a imprensa precisa observar determinadas regras no uso de uma língua a fim de transmitir informações de interesse público, a Contabilidade também deve obedecer a regras próprias para comunicar eventos de natureza econômica. Em seguida, salienta-se que a inobservância de certas regras não apenas poderá gerar interpretações distorcidas, mas também acarretar riscos de penalidades para o contador em razão de má representação, falsidade ideológica ou perjúrio.

Anthony et al. (1975, p. 12-13) afirmam que a Contabilidade é apropriadamente denominada a linguagem dos negócios. Porém, consideram que a tarefa de assimilar conhecimentos contábeis torna-se complexa porque muitas palavras utilizadas em Contabilidade acabam evocando significados diferentes daqueles que com elas são evocados na linguagem comum. Reforçando o entendimento de que a Contabilidade é uma espécie de linguagem, os referidos autores destacam a necessidade de adaptação da terminologia contábil às mudanças que ocorrem na sociedade. Em suas palavras, temos:

A Contabilidade também se assemelha a uma linguagem, na medida em que algumas de suas regras são definidas enquanto outras não. Há diferenças de opinião entre contadores a respeito de como um determinado evento deveria ser relatado, da mesma forma que gramáticos divergem em relação a muitos pontos de estrutura, pontuação e escolha de palavras numa sentença. Finalmente, línguas evoluem em resposta às necessidades mutantes da sociedade, assim como a Contabilidade. (tradução livre)

Riahi-belkaoui (1995) ensina que um dos mais importantes propósitos da Contabilidade é comunicar informações relevantes para diversos tipos de usuários e que, para tanto, essa disciplina se vale de um conjunto de palavras e técnicas típicas de uma linguagem específica. Na obra referenciada, o autor sempre alude à Contabilidade como a linguagem dos negócios e explica que ela assim se caracteriza por representar fenômenos no mundo dos negócios assim como a linguagem natural representa fenômenos no mundo real. Em sua percepção, a noção 
da Contabilidade como linguagem repousa nos seguintes elementos: símbolos e regras gramaticais. Os símbolos são os objetos lingüisticos utilizados para identificar conceitos específicos; as regras gramaticais são os mecanismos sintáticos para "criar os dados contábeis", conclui o autor.

Adelberg (1979) compartilha desse mesmo entendimento acrescentando que se a linguagem contábil deve ser utilizada como instrumento gerador de uma comunicação eficiente, deve haver consenso entre as partes envolvidas no processo de comunicação das informações contábeis quanto às regras sintáticas e semânticas que presidem a elaboração das demonstrações.

Jain (1973) também considera que a Contabilidade é uma linguagem de negócios e que ela possui muitas semelhanças com a linguagem natural. Esse autor afirma que assim como a gramática possui um conjunto de regras que permitem a construção de sentenças, a Contabilidade também se vale de critérios básicos, que constituem uma espécie de gramática financeira cujo papel é ajudar a descrever transações com razoável acurácia. Na mesma obra, Jain (1973, p. 78) complementa esse raciocínio da seguinte maneira:

O CPA examina a aplicação das regras contábeis da mesma forma que um proficiente de uma língua atesta a correção gramatical de uma sentença. Regras contábeis definem a estrutura da Contabilidade assim como a gramática define a estrutura inerente a uma linguagem natural. (tradução livre)

Mckay e Rosa (2000, p. 1) definem a Contabilidade como uma linguagem de negócios e consideram que um dos maiores desafios da profissão ainda é ajudar os usuários das informações contábeis a interpretá-las adequadamente. Considera-se que embora os contadores gastem muito tempo organizando sistemas contábeis, cuidando de registros e de outras tarefas similares, na prática suas atividades apenas se iniciam com tais procedimentos. Finalmente, argumenta-se que até certo ponto a concretização da atividade contábil e a própria medida do sucesso profissional dependem da habilidade com que se comuniquem as referidas informações.

Como se observa, a Contabilidade tem sido reconhecida por muitos autores como um tipo de linguagem ou, mais especificamente, como uma linguagem de negócios. Em geral, considera-se que essa abordagem permite melhor entendimento do processo de comunicação das informações contábeis e do significado que elas devem apresentar para cada estrato de usuário. A partir de então, parece-nos razoável explorar a relação que pode existir entre Contabilidade e Semiótica, já que esta tem por finalidade estudar todos os tipos de linguagem.

\section{A RELAÇÃO ENTRE CONTABILIDADE E SEMIÓTICA}

Partindo do pressuposto de que a Contabilidade de fato é uma espécie de linguagem e considerando também que a Semiótica estuda todas as linguagens sob os aspectos sintático, semântico e pragmático, diversos autores sugerem existir forte relação entre as duas disciplinas. Mais particularmente, entende-se que a Semiótica pode fornecer metodologia útil para se interpretar relatórios e corrigir eventuais distorções que se manifestem no processo de geração e comunicação das informações contábeis. Ao nível sintático, procura-se compreender as informações contábeis à luz do conjunto de normas e princípios que regem a sua produção. Ao nível semântico, o objetivo é verificar a fidelidade da representação, isto é, se existe correspondência entre as descrições alfanuméricas que integram as demonstrações contábeis e os atributos dos eventos que elas buscam representar. Finalmente, ao nível pragmático, a preocupação é verificar o grau de adequação das informações contábeis aos objetivos de seus destinatários. 
As três dimensões semióticas da informação contábil (sintática, semântica e pragmática) foram contempladas no Statement of Financial Accounting Concepts No. 2, editado pelo FASB em 1980, onde se trata das características qualitativas da informação contábil. Nesse documento, afirma-se, por exemplo, que a fidelidade da representação é um dos requisitos vitais à informação contábil e que essa qualidade é alcançada quando existe correspondência entre uma medida ou descrição e o fenômeno que se pretende representar. O FASB acrescenta que o grau de fidelidade da representação contábil depende em muito do significado das palavras utilizadas no processo de evidenciação. Por isso, esse órgão considerou também que a compreensibilidade é outro requisito fundamental à utilidade da informação contábil. Temos, aqui, a dimensão semântica da informação contábil.

De igual forma, quando o FASB conclui que o objetivo principal da Contabilidade é fornecer informações úteis para orientar decisões de investimento, crédito e outras semelhantes, esse órgão põe em destaque a dimensão pragmática da informação, ou seja, o efeito que ela deve produzir para o usuário. Aliás, nesse aspecto, em particular, o FASB salienta que a evidenciação deve servir, preferencialmente, a usuários que carecem de autoridade para influenciar o escopo das informações contábeis ou que tenham capacidade restrita para interpretá-las.

Mas, afinal, em que se baseia a tese de que existe relação entre Semiótica e Contabilidade e quais as consequiências resultantes desse entendimento? Para responder, talvez seja oportuno mencionar as seguintes considerações de Morris (1976, p. 10-11), um dos principais organizadores da teoria semiótica:

\footnotetext{
A semiótica fornece uma linguagem geral aplicável a qualquer linguagem ou signo especial, e por isso mesmo, aplicável à linguagem da ciência e aos signos específicos que são usados na ciência. (...) se a semiótica é uma ciência coordenada às outras ciências, pelo fato de estudar as coisas ou as propriedades das coisas em função de signos, ela é também o instrumento de todas as ciências, visto que toda ciência faz uso de signos e expressa os seus resultados em termos de signos. (grifos nossos)
}

Aliás, na própria literatura contábil, encontram-se diversos autores que compartilham do entendimento de que a Contabilidade, como sistema destinado a identificar, mensurar e comunicar eventos de natureza econômica, de fato se relaciona com a Semiótica. Exemplo dessa natureza pode ser encontrado em Mason e Swanson (1981, p. 11), tendo em vista que eles interpretam a mensuração como um signo quantitativo, baseando-se no fato de que ela utiliza numerais para representar alguns atributos associados a um objeto ou evento de interesse.

Para explicar como a mensuração contábil se relaciona com a semiótica, Mason e Swanson começam por destacar que Charles W. Morris (1901 - 1979) classificou a teoria dos signos em três subdivisões principais: sintática - signos e suas relações com outros signos; semântica signos e suas relações com o mundo externo; e pragmática - signos e suas relações com os usuários da informação. Após a caracterização de cada uma destas subdivisões, Mason e Swanson (1981, p. 12) expõem o seguinte entendimento a respeito do vínculo que se estabelece entre mensuração contábil e semiótica:

Em nosso ponto de vista, a mensuração científica tradicional enfoca primeiramente o nível semântico. Lida com a questão, 'quão bem o signo numérico reflete a natureza real do objeto ou evento ao qual se refere?' Por outro lado, a mensuração aplicável a decisões gerenciais diz respeito ao nível pragmático. Envolve-se com a questão, 'quão bem o signo numérico se relaciona com os usuários e seus objetivos?' (tradução livre) 
Desse modo, Mason e Swanson consideram que os eventos possuem atributos ou características qualitativas observáveis que podem ser mensurados, tais como cumprimento, peso, valor monetário etc. No mesmo trabalho, estes autores explicam que o conceito científico de mensuração é essencialmente de natureza semântica, uma vez que tal procedimento busca associar números a objetos ou eventos a fim de que suas propriedades ou atributos sejam fielmente representados. Acrescenta-se que se os cientistas pretendem descrever, explicar, ou predizer a natureza dos objetos ou eventos, então seu esforço é eminentemente semântico.

De forma semelhante, Ijiri (1975, p. 40-43) aborda a mensuração contábil como uma linguagem especial que representa fenômenos do mundo real por meio de símbolos numéricos. Esse autor considera que o principal objetivo de uma linguagem é comunicar o estado de alguma coisa e que, no caso da mensuração, o seu propósito fundamental é comunicar certas propriedades de eventos econômicos da entidade. Explorando o aspecto semântico da evidenciação, destaca-se que os dados produzidos como outputs da mensuração não têm nenhuma utilidade em si mesmos, isto é, quando apartados de sua função de representar o estado de outros objetos.

Para facilitar o entendimento dessa questão, Ijiri explica que os símbolos utilizados para transmitir informação sobre o estado de alguma coisa são chamados surrogates (substitutos) e as coisas ou fenômenos por eles representados são chamados principals (essências). Continuando, o autor esclarece que, desse modo, o principal é o que nos interessa primordialmente, ao passo que os surrogates apenas atraem nossa atenção na medida em que fornecem informações sobre o estado do principal. Transpondo estas idéias para o campo da evidenciação contábil, o autor completa:

\footnotetext{
Claramente, demonstrativos contábeis constituem exemplo típico de substituições, já que as pessoas se interessam por tais demonstrativos não por causa de sua beleza artística, mas porque buscam representar alguns aspectos da situação econômica de uma empresa. Para alcançar o objetivo a que se destina o substituto, seu usuário deve ser capaz de decodificar as mensagens para descobrir o estado do principal. (1975, p. 41, tradução livre)
}

Etheridge (1991) recomenda o uso de conceitos da semiótica para se obter um melhor entendimento das características do processo de comunicação das informações contábeis e, assim, poder-se avaliar com maior precisão suas dimensões semântica, sintática e pragmática. Em seu trabalho intitulado An Examination of Semiotic Theories of Accounting Accruals (1991), o autor lembra que a semiótica envolve as teorias semântica, sintática e pragmática e, adicionalmente, faz referência a diversos estudos que introduziram conceitos de semiótica na Contabilidade.

Nakagawa e Pretto (2000) também sugerem que se utilizem conceitos derivados da Semiótica para aprimorar o processo de evidenciação contábil. No trabalho intitulado $A n$ Interdisciplinary view of Accountancy in Brazil, os referidos autores explicam que a semiótica, como ciência dedicada ao estudo dos signos, pode contribuir para aprimorar a Contabilidade à medida que nos conduza a uma melhor percepção dos eventos econômicos que impactam o desempenho das organizações.

Baseando-se em trabalhos de Peirce (1914), um dos precursores das teorias semióticas, Nakagawa e Pretto esclarecem que essa disciplina pode fornecer instrumental metodológico para auxiliar na identificação, observação e análise dos fenômenos que provocam variações patrimoniais. Como se observa, a sugestão dos autores revela preocupação em melhorar o poder informativo da evidenciação contábil para que a mesma possa agregar mais valor às decisões econômicas das entidades. 


\section{O PAPEL DA ANÁLISE DE BALANÇOS NA INTERMEDIAÇÃO FINANCEIRA}

Como ponto de partida, consideramos necessário tecer algumas considerações acerca da atividade de intermediação financeira no contexto da economia. A literatura demonstra que os sistemas econômicos capitalistas valem-se de um grande número de instituições que se encarregam de captar recursos junto a elementos que se propõem a poupar e, em seguida, transferem tais recursos para os agentes que estão dispostos a realizar investimentos. Esse ato de investir é visto como a mola mestra do processo de desenvolvimento econômico de um país.

Nesse sentido, o termo investimento deve ser interpretado como formação real de capital, isto é, acréscimo ao estoque de recursos produtivos, do qual depende o aumento do potencial de produção de bens e serviços. Em termos de unidades empresariais, investimento significa qualquer aplicação de recursos que tenha por finalidade a obtenção de lucros futuros.

Contudo, é necessário esclarecer que nas modernas economias capitalistas quem poupa não é necessariamente quem investe, ou seja, nem todos os recursos que deixam de ser utilizados em consumo corrente são canalizados para a formação de capital real. Isto dependerá não só da existência de agentes econômicos dispostos a investir, transformando a poupança financeira em poupança real, mas também da existência de uma estrutura de intermediação financeira atuante, que efetivamente promova a canalização da poupança para investimentos. Após essa rápida caracterização do que vem a ser intermediação financeira e de seu papel nos sistemas econômicos, passaremos a apreciação dos chamados instrumentos de decisão de crédito. O objetivo é demonstrar que a literatura corrente privilegia a Análise de Balanços como um dos principais instrumentos de decisões de crédito, ainda que sujeita a determinadas limitações.

A Análise de Balanços se caracteriza como instrumento de decisão de crédito na medida que proporciona informações para se dimensionar riscos associados aos agentes econômicos interessados na obtenção de recursos financeiros. A qualidade das decisões de crédito fica a depender, pelo menos até certo ponto, do grau com que as demonstrações contábeis reflitam a posição econômico-financeira das entidades envolvidas no processo e, principalmente, da percepção que os usuários tenham dos fenômenos que se busca representar por meio de tais demonstrações.

De acordo com Matarazzo (1995), um dos elementos de grande importância na tomada de decisões econômico-financeiras é a análise das demonstrações contábeis, haja vista que através desse procedimento pode-se avaliar os efeitos de certos eventos sobre a situação da empresa. Na opinião desse autor, o diagnóstico de uma empresa quase sempre começa com uma rigorosa Análise de Balanços, cuja finalidade é identificar pontos críticos e permitir que se adotem as medidas corretivas necessárias. No caso de decisões ligadas à intermediação financeira, a Análise de Balanços pode contribuir para indicar a conveniência ou não de se conceder créditos, por exemplo.

No mesmo trabalho, Matarazzo destaca que para conceder crédito a curto prazo os bancos comerciais não apenas observam a situação atual do cliente, mas também procuram identificar nas demonstrações contábeis elementos que lhes permitam formar uma imagem da sua situação futura. Nesse caso, a preocupação é selecionar os clientes que se apresentem em melhores condições de honrar seus compromissos, minimizando o grau de risco a que fica sujeita a instituição financeira.

Do ponto de vista estratégico, é também um meio de se identificar e selecionar os melhores clientes de amanhã. Com isso, pode-se obter vantagem competitiva sobre os concorrentes. Matarazzo explica que essa é uma das razões pelas quais embora um banco comercial atribua 
maior importância à análise de curto prazo, não despreza elementos de longo prazo, como rentabilidade e a capitalização do cliente.

Ainda segundo Matarazzo, diferentemente dos bancos comerciais, os que lidam com a concessão de financiamento a grandes empresas estão essencialmente preocupados com a situação futura de seus clientes. Por isso, eles buscam na Análise de Balanços indicadores da saúde econômico-financeira de seus clientes em horizontes mais dilatados. Nesse caso, em particular, as demonstrações contábeis devem fornecer elementos que permitam análises de tendências, previsões da situação futura do cliente etc. Matarazzo destaca que nos casos de financiamento mais expressivos, torna-se necessária a elaboração de projetos em que a Análise de Balanços é apenas uma parte, porém não em posição secundária.

Iudícibus (1998) também destaca que o desenvolvimento da Análise de Balanços esteve associada a necessidades de intermediação financeira, especialmente quando se envolvem instituições governamentais de desenvolvimento, tanto em nível regional como nacional. Esse autor destaca que tais instituições normalmente exigem, como parte do projeto de financiamento, uma completa análise econômico-financeira. Outro importante aspecto destacado por Iudícibus é a função que a Análise de Balanços pode desempenhar em economias de mercado bem desenvolvidas. Na avaliação desse autor, um dos motivos que levam o investidor a adquirir ações de determinadas companhias reside nos resultados das análises realizadas com relação aos balanços das empresas.

Ainda segundo Iudícibus, não se tem notícia de um caso sequer em que decisões de investimentos foram tomadas apenas com base em análises de demonstrações contábeis, mas também, segundo o autor, não é conhecido nenhum caso de sucesso a longo prazo no investimento em ações em que a análise de relacionamentos contábeis não desempenhe algum papel relevante.

Assaf Neto (1993) nos ensina que a Análise de Balanços tem sofrido evolução conceitual e prática no sentido de abranger esquemas de interpretação que não se limitem aos indicadores verticais e horizontais, bem como ao cálculo de índices tradicionais. Esse autor nos leva ao entendimento de que uma Análise de Balanços em sentido mais amplo requer interpretações de fenômenos conjunturais que exercem influências sobre o desempenho das empresas. Destaca-se que desse modo pode-se avaliar de maneira mais eficaz sua posição atual tendências futuras. A preocupação subjacente é a de que o analista não restrinja sua análise unicamente aos registros contábeis publicados, mas que considere também fatores relacionados ao ambiente em que os agentes econômicos operam.

Nessa mesma linha de raciocínio, Vertes (1972) destaca que a tarefa de analisar balanços não consiste apenas em determinar a situação financeira ou econômica da entidade e afirmar de maneira estanque que a mesma se encontra em condições debilitadas, por exemplo. Muito mais do que isso, completa o autor, a Análise de Balanços deve descobrir as razões pelas quais a empresa se encontra nessa ou naquela situação.

Trata-se, pois, de um esforço mais amplo, de uma busca que vá ao encontro da essência dos fenômenos econômicos responsáveis pelas mutações patrimoniais. Como o próprio autor ressalta, hoje a Análise de Balanços deve contribuir para indicar as transações que melhoram a situação da empresa, as que pioram, ou seja, deve se preocupar com as causas das variações patrimoniais. Falar do passado não é suficiente. É necessário apontar caminhos e perspectivas para o futuro.

Braga (1975), ao relacionar procedimentos de Análise de Balanços à atividade de intermediação financeira, afirma que essa técnica tem por finalidade observar e confrontar os elementos patrimonial, visando ao conhecimento minucioso de sua composição qualitativa e de sua expressão quantitativa, de modo a revelar os fatores antecedentes e determinantes da situação atual. Destas considerações, depreende-se que a Análise de Balanços não é uma 
mera obtenção de um conjunto de índices, mas antes de tudo uma atividade de natureza interpretativa. Com ela, pretende-se alcançar a essência dos fenômenos econômicos responsáveis pela produção dos resultados que estão sendo avaliados.

Iudícibus (1998) põe em destaque esse aspecto quando afirma que a Análise de Balanços se caracteriza como uma arte de saber extrair relações úteis, para o objetivo econômico que tivermos em mente, dos relatórios contábeis tradicionais e de suas extensões e detalhamentos, quando cabível. Desse modo, o autor quer salientar que a qualidade da análise dependerá da sensibilidade do analista, de sua capacidade de fazer relacionamentos corretos, do conhecimento que ele tem da empresa, processos produtivos, mercados etc. A análise sob esse ponto de vista é essencialmente fenomenológica.

Como se observa, em linhas gerais, a literatura revela que as decisões de intermediação financeira baseiam-se fortemente em análises de balanços. Uma das razões é que a própria concessão do crédito fundamenta-se na expectativa de que o credor seja capaz de restituir em prazo hábil o capital emprestado com a devida remuneração. Um segundo motivo é que outros recursos de predição dessa capacidade normalmente padecem de alta dose de subjetividade. Como exemplo, teríamos: mudança em tecnologias, alterações em mercado, concorrência, conjuntura político-econômica etc. Diante disso, a Análise de Balanços surge como um mecanismo capaz de fornecer informações mais objetivas, entre as quais poderíamos destacar: a posição relativa do cliente no ramo de atividade em que atua, capacidade de pagamento, desempenho e riscos do setor etc.

\section{A ANÁLISE SINTÁTICA dAS DEMONSTRAÇÕES CONTÁBEIS}

A Teoria da Contabilidade sugere que as informações contábeis devem ser analisadas em três níveis distintos: sintático, semântico e pragmático. Ao nível sintático, o objetivo da análise é verificar se tais informações obedecem a um conjunto de regras significativas, de modo que o usuário das demonstrações contábeis possa compreender o seu sentido e suas limitações. Por exemplo, quando alguém se depara com a expressão LUCRO, é preciso que se tenha em mente que o valor a ela atribuído resulta de um agregado de parcelas positivas e negativas que se combinam sob determinadas regras. Para exemplificar, salientamos que uma dessas regras poderia ser o "custo histórico como base de valor" ou ainda o chamado "confronto entre receitas e despesas".

Referindo-se a problemas de ordem sintática na evidenciação contábil, Hendriksen e Breda (1999) afirmam que o conceito de lucro nem sempre é bem compreendido porque ele resulta de um conjunto de regras e convenções que geralmente não encontram correspondência com fenômenos do mundo real. Destaca-se que regras como regime de competência, realização e confronto entre receitas e despesas nem sempre são compreendidas porque, de fato, não possuem significados foram da lógica contábil. Aliás, ainda segundo Hendriksen, como LUCRO é um somatório de itens positivos e negativos, se um deles não for compreendido satisfatoriamente, o lucro líquido também deixa de ser compreendido.

Daí a necessidade de se efetuar uma Análise de Balanços também do ponto de vista sintático, isto é, levando em consideração o significado das regras mediante as quais são geradas as informações contábeis. Voltando-nos para o foco deste trabalho, que é a otimização de decisões econômico-financeiras, diríamos que sem uma compreensão das informações contábeis do ponto de vista sintático não é possível aquilatar riscos, realizar predições, interpretar índices etc.

Para se ter uma idéia mais clara acerca dessa questão, consideremos duas empresas, A e B, que avaliam seus estoques pelos métodos PEPS e UEPS, respectivamente. Mesmo que ambas estejam niveladas quanto a preços de compra e venda e que possuam fluxos de mercadorias 
absolutamente idênticos, ainda assim certos quocientes extraídos das demonstrações contábeis se apresentarão muito distintos.

A título de exemplo, apresentamos o seguinte relatório de vendas, acompanhado da Demonstração de Resultado do Exercício:

\begin{tabular}{|c|c|c|c|c|c|}
\hline $\begin{array}{c}\text { Métodos de } \\
\text { Avaliação }\end{array}$ & $\begin{array}{c}\text { Qtde. } \\
\text { Vendidas }\end{array}$ & R\$/unid & Receita & CMV & Resultado \\
\hline PEPS & 500 & 10 & 5.000 & $(2.000)$ & 3.000 \\
\hline UEPS & 500 & 10 & 5.000 & $(4.000)$ & 1.000 \\
\hline
\end{tabular}

\begin{tabular}{|l|l|l|}
\hline \multirow{2}{*}{ Demonstração do Resultado } & \multicolumn{2}{|c|}{ Métodos de Avaliac̃o de Estoques } \\
\cline { 2 - 3 } Receita Bruta & PEPS & UEPS \\
(-) CMV & 5.000 & 5.000 \\
(=) Lucro Bruto & $(2000)$ & $(4.000)$ \\
(-) Despesas Operacionais & 3.000 & 1.000 \\
(-) Despesas Financeiras & $(500)$ & $(500)$ \\
(=) Lucro Antes do I.R. & $(100)$ & $(100)$ \\
(-) I.R. & 2.400 & 400 \\
(=) Lucro Líquido & $(240)$ & $(40)$ \\
\hline
\end{tabular}

Quadro: Relatório de Vendas e DRE

Para demonstrar que a correta interpretação dos índices fica a depender do conhecimento das regras sintáticas, passaremos ao cálculo dos seguintes quocientes:

\section{Quociente de Retorno sobre o Patrimônio Líquido}

Fórmula: LUCRO LÍQUIDO / PATRIMÔNIO LÍQUIDO

Admitindo-se um Patrimônio Líquido inicial de $\mathrm{R} \$ 10.000,00$ e que o único valor a ele agregado seja o lucro apurado no período, teríamos os seguintes quocientes:

Empresa A (PEPS): QRPL= $2.160 / 12.160,00$, ou seja, 17,76\%

Empresa B (UEPS): QRPL= $360 / 10.360$,ou seja, 3,47 \%

\section{Quociente de Participação de Capitais de Terceiros sobre Capitais Próprios}

Fórmula: EXIGÍVEL TOTAL / PATRIMÔNIO LÍQUIDO

Admitindo-se um exigível de 5.000,00 em cada um dos períodos, teríamos:

Empresa A (PEPS): 5.000 / 12.160, ou seja, 41,11\%

Empresa B (UEPS): 5.000 / 10.360, ou seja, 48, 26\%

Como se observa, com o mesmo volume de vendas e com faturamento absolutamente idêntico, obtiveram-se quocientes completamente distintos para cada caso. Ora, diante disso, a questão que se apresenta é a seguinte: sem uma compreensão do significado dessa regra sintática (método de avaliação), é possível interpretar adequadamente um índice dessa natureza? Que contribuição tais índices podem oferecer para a mensuração de riscos, seleção de tomadores de crédito etc.? Enfim, que serventia terá um índice dessa natureza sem uma compreensão adequada da regra pela qual se mensurou o lucro? 
Portanto, é com absoluta razão que Hendriksen se manifesta sobre o conceito de lucro ao nível sintático, afirmando que para a maioria das pessoas o mesmo se apresenta incompreensível. Afirma-se que a adequada compreensão do conceito de lucro fica a depender da compreensão das regras sintáticas que governam a sua mensuração. Esta é também uma das razões pelas quais a maioria das obras que se dedicam à Análise de Balanços começa por explicar o sentido dos princípios contábeis. Aliás, mais do que isso, é costume iniciar-se pelos próprios objetivos da contabilidade.

\section{A ANÁLISE SEMÂNTICA DAS DEMONSTRAÇÕES CONTÁBEIS}

Do ponto de vista semântico, espera-se que as descrições alfanuméricas dos eventos retratados nas demonstrações contábeis guardem correspondência com a realidade.

Referindo-se ao problema de ordem semântica, Hendriksen e Breda (1999) afirmam que a relevância semântica das informações contábeis é alcançada quando o destinatário da informação compreende o significado pretendido da informação divulgada. Ao tratar da fidelidade da representação, esse autor se pronuncia nos seguintes termos: "Para que alguém confie em informações, é essencial que elas representem fielmente os fenômenos que pretendem representar" (HENDRIKSEN e BREDA, 1999, p. 99).

Para ilustrar, Hendriksen e Breda se valem do seguinte exemplo mencionado pelo FASB, no Statement of Financial Accounting Concepts $n^{\circ} .2$ :

Um teste de ortografia é aplicado oralmente a um grupo de estudantes. As palavras são lidas em voz alta pelo examinador, e os estudantes devem escrevê-las. Alguns estudantes, embora geralmente possam soletrar bem, são reprovados no teste. $\mathrm{O}$ motivo, na realidade, é o de que têm problemas de audição. O escore do teste se destina a medir a capacidade de soletrar, mas, na verdade, está parcialmente medindo a acuidade auditiva. $O$ escore do teste não possui fidelidade efetiva de representação.

Portanto, ao analisar as demonstrações contábeis é preciso considerar se existe uma fidelidade de representação em nível satisfatório. Isso implica não apenas fazer um julgamento dos termos utilizados para designar os eventos econômicos, mas também das regras de mensuração. Quanto aos termos que se utilizam na evidenciação contábil, Hendriksen e Breda (1999) consideram que tão importante quanto a forma das demonstrações são as descrições numa demonstração e o grau de detalhamento empregado.

No mesmo trabalho, argumenta-se que título e descrições apropriados dos itens contidos nas demonstrações podem ser esclarecedores para o leitor, mas termos obscuros só podem levar à confusão ou incompreensão. Hendriksen acrescenta que termos técnicos podem ser úteis caso possuam significados precisos e sejam geralmente bem conhecidos, mas muitos termos técnicos, em Contabilidade, carecem dessa precisão. Para contornar essa dificuldade, recomenda-se o uso de termos descritivos geralmente empregados por analistas financeiros e outros leitores informados.

De modo semelhante, alerta-se que a tão defendida uniformidade terminológica só é útil quando os significados são claros e os itens são semelhantes em todos os casos nos quais um dado termo é aplicado, completam Hendriksen e Breda (1999).

Infelizmente, a realidade demonstra que de fato muitos termos empregados na evidenciação contábil deixam de ser compreendidos pelos usuários das demonstrações. Dias Filho e Nakagawa (2001), por exemplo, fazem referência a situações em que palavras como depreciação, equivalência patrimonial, imposto de renda diferido e provisões são pouco compreendidas. Os autores comentam que essa dificuldade tanto pode surgir do hábito de se atribuírem significados técnicos a palavras que são utilizadas com sentido diferente no meio 
comum, como também em função do uso indiscriminado de expressões demasiadamente técnicas. Hendriksen e Breda (1999) também fazem alusão a este fato afirmando que muitos termos em contabilidade se apresentam completamente destituídos de valor semântico. Como exemplo, esse autor cita que a expressão despesas diferidas não encontra qualquer interpretação específica além dos processos estruturais que lhe deram origem.

Como se vê, o problema de ordem semântica é algo que deve ser considerado no processo de análise das demonstrações contábeis. Aliás, há de se considerar também que a informação contábil já pode nascer enviesada se os elementos responsáveis pela coleta de dados, como os apontadores, por exemplo, não conseguirem interpretar adequadamente os eventos econômicos com os quais se defrontam. Isso significa que a função interpretativa no processo contábil é um fator que não se restringe apenas ao usuário das informações contábeis, mas envolve todos os elementos que de uma forma ou de outra estão lidando com os eventos contábeis.

Iudícibus (1997) também destaca a importância de se utilizar uma terminologia clara e relativamente simplificada. Esse autor salienta que termos e grupos obscuros como "pendente", "resultado pendente" ou mesmo "resultado de exercícios futuros" devem ser evitados, por não serem precisos.

Como já salientamos, o FASB, ao definir as características qualitativas da informação contábil, também manifestou preocupação com o problema de ordem semântica, tanto que elegeu a compreensibilidade com um dos principais atributos das informações contábeis. Na opinião desse órgão, a primeira condição para que as informações contábeis possam ser úteis ao processo decisório é que elas se apresentem compreensíveis.

Portanto, em se tratando de decisões de crédito, a Análise de Balanços deve contemplar também aspectos de natureza semântica. Em primeiro lugar, deve verificar se existe correspondência entre a realidade e a expressão monetária que foi atribuída a determinada categoria de eventos econômicos. Nisso, tem-se um julgamento da adequação da representação numérica do fenômeno. Em seguida, é necessário verificar se as descrições, títulos e evidenciações narrativas guardam correspondência satisfatória com o que elas buscam representar.

O que se deseja é que as mensagens contábeis despertem, aproximadamente, a mesma reação que os usuários das demonstrações teriam caso estivessem observando por si próprios os eventos nelas retratados. Para que isso aconteça, duas condições fundamentais se impõem. A primeira é que haja correspondência entre a realidade e o retrato que dela se construiu através das mensagens contábeis. E a segunda é que haja congruência entre os significados que produtores e usuários venham a atribuir a tais mensagens. É por esse motivo que Adelberg (1979) e outros autores propõem que se verifique, periodicamente, se as principais categorias de usuários das demonstrações contábeis conseguem compreender as mensagens nelas contidas.

Como se observa, a tarefa de analisar balanços realmente não pode ser entendida como uma simples obtenção de índices, mas algo bem mais profundo que busca averiguar a essência dos fenômenos. Isso pressupõe uma boa acuidade de percepção guiada pelo domínio das técnicas contábeis e também pela compreensão das próprias limitações a que estão sujeitos os sistemas contábeis. Tudo isso implica compreender que a informação contábil, enquanto produto de percepções humanas, está sujeita a algum viés, mesmo que se observem os chamados princípios e convenções geralmente aceitos. Ressalvamos, finalmente, que isso não lhe tira o mérito, mas apenas nos dá uma indicação de como devem ser analisadas e utilizadas.

\section{ANÁLISE PRAGMÁTICA DAS DEMONSTRAÇÕES CONTÁBEIS}


Do ponto de vista pragmático, para que se analisem adequadamente as demonstrações contábeis, é preciso verificar se existe compatibilidade entre elas e os objetivos a que se destinam. Nesse ponto, é necessário considerar o que pensa o FASB a respeito da finalidade da informação contábil. Como mencionamos anteriormente, o entendimento desse órgão é que as informações contábeis devem servir para orientar decisões relativas a crédito, investimentos e outras correlatas.

Além disso, é importante considerar também que a preocupação maior do FASB recai sobre as camadas de usuários que não detêm poder suficiente para influenciar o processo de produção das citadas informações. Obviamente, tais usuários estariam representados prioritariamente por fornecedores, pequenos acionistas, clientes e outros semelhantes. Aliás, o próprio FASB deixa isso muito claro quando afirma no Statement of Financial Accounting Concepts $\mathrm{n}^{\mathrm{o}} 1$ que:

O objetivo da divulgação financeira é proporcionar informação que ajude investidores, credores e outros usuários, presente e em potencial, a avaliar os volumes, a distribuição no tempo e a incerteza de possíveis fluxos de caixa em termos de dividendos ou juros.

Destas considerações, observa-se que a informação contábil não possui um fim em si mesma, mas somente pode ser útil quando se apresenta em condições de melhorar a qualidade das decisões de determinados usuários. Aqui, temos a chamada relevância pragmática da informação contábil, que também deve ser considerada no processo de Análise de Balanços. Não adianta, pois, utilizar índices deste ou daquele tipo se os mesmos não resultam de dados afinados com os objetivos dos usuários. Por exemplo, se para determinado modelo decisório o ideal é mensurar estoques pelo custo de reposição, não importa que se utilizem índices de rotação de estoques ou de liquidez corrente baseados em custo histórico. Nesse caso, a informação estaria distante dos objetivos do usuário, ou seja, ficaria empobrecida no que se refere ao valor pragmático.

Desse modo, quer-se afirmar que informação relevante não é aquela que se afina apenas com determinados critérios técnicos, mas a que se mostra em melhores condições de ajudar os usuários a tomar decisões de melhor qualidade. Esse é um problema que deve ser considerado no processo de analise de balanços, sobretudo quando se trata de otimizar decisões econômico-financeiras.

Hendriksen e Breda (1999, p. 97) esclarecem que a informação relevante, do ponto de vista pragmático, é aquela que seja pertinente e esteja associada, de maneira útil, a ações que visem facilitar ou aos resultados desejados. Em seguida, esse autor acrescenta que a relevância para tomada de decisões, isto é, o valor pragmático, é alcançada quando a informação facilita a tomada de decisões pelos usuários.

Tudo isso aponta para a necessidade de se identificar o modelo decisório do usuário não apenas para definir o tipo de informação que é lhe mais adequada, mas também para analisar se a informação oferecida é compatível com os objetivos de seus destinatários. Nesse ponto, pode-se argumentar que nem sempre os modelos decisórios dos usuários podem ser identificados ou que, em muitas circunstâncias, nem eles mesmos conseguem esboçar seu modelo decisório. Isso realmente é verdadeiro, mas em nada reduz a responsabilidade de se produzir a informação que de fato contemple a necessidade do usuário.

Desse modo, desejamos enfatizar que, uma análise pragmática das informações contábeis pressupõe a consideração de que não basta oferecer um conjunto de informações quaisquer. Pelo contrário, é necessário identificar as necessidades médias das diversas categorias de usuários de modo que tais informações possam, de fato, contribuir para melhorar a qualidade das decisões. 


\section{CONCLUSÕES}

A literatura confirma que a Análise de Balanços realmente pode servir à otimização de decisões de crédito. Porém, esse papel não pode ser cumprido por uma análise que se baseie apenas na mera obtenção de índices das demonstrações financeiras, sem qualquer preocupação adicional com a qualidade dos dados utilizados e menos ainda com a interpretação dos fenômenos econômicos nelas retratados. Pelo contrário, a análise que pode agregar valor a decisões de natureza econômico-financeira deve se diferenciar pela qualidade do ato reflexivo e pelas habilidades de interpretação dos fenômenos que cada índice ou quociente pretende retratar.

Considerando que a Contabilidade tem sido definida por muitos autores com uma linguagem de negócios, é provável que a Semiótica possa contribuir para melhorar a qualidade da análise de balanços, haja vista que este ramo do conhecimento estuda todo tipo de linguagem sob os aspectos sintático, semântico e pragmático. A Teoria da Contabilidade de fato confirma que as informações contábeis podem ser analisadas sob estas três dimensões.

Sob o aspecto sintático, o analista deve considerar que as informações contábeis estão circunscritas a um conjunto de normas que acabam definindo os seus limites e o próprio grau de validade. Sem essa compreensão, corre-se o risco de formular conclusões distorcidas acerca do significado de cada índice.

A análise semântica, por sua vez, nos levaria a verificar se existe correspondência satisfatória entre as descrições alfanuméricas e os eventos econômicos que elas buscam representar.

Por fim, a análise pragmática busca verificar até que ponto as informações contábeis estão sintonizadas com os objetivos de seus usuários, isto é, se elas se apresentam em condições de contribuir para melhorar a qualidade de suas decisões.

Em termos práticos e de forma resumida são estas as contribuições que a Semiótica pode oferecer ao processo de análise de balanços, em sentido geral.

\section{REFERÊNCIAS}

ADELBERG, Arthur Harris. A Methodology for measuring the understandability of financial report messages. Journal of Accounting Research, Autumn, 1979.

ANTHONY, Robert Newton et al. Accounting: text and cases. Chicago: Irwin, 1975.

ASSAF NETO, Alexandre. Estrutura e Análise de Balanços: Um enfoque EconômicoFinanceiro. São Paulo: Atlas, 1993.

BRAGA, Roberto. Fundamentos e Técnicas de Administração Financeira. São Paulo: Atlas, 1975.

DIAS FILHO, José Maria, NAKAGAWA, Masayuki. Análise do Processo da Comunicação Contábil: Uma contribuição para a solução de problemas semânticos, utilizando conceitos da teoria da comunicação. Revista Contabilidade e Finanças, FEA/USP, São Paulo, 2001.

ETHERIDGE, Harian Lynn. An examination of Semiotic Theories of Accounting Accruals. Unpublished Ph. D. dissertation, Louisiana State University, 1991. 
FINANCIAL ACCOUNTING STANDARDS BOARD-FASB. Statement of Financial Accounting Concepts No. 2, Qualitative Characteristics of Accounting Information, May 1980.

HENDRIKSEN, Eldon S.; BREDA, Michael F. Van. Teoria da contabilidade. Editora Atlas, 5. ed. São Paulo, 1999.

HORNGREN, Charles T. Accounting for management control. Englewood Cliffs, NJ: Prentice-Hall, 1974.

IJIRI, Y. Theory of accounting measurement. Sarasota, FL: American Accounting Association, 1975.

IUDÍCIBUS, Sérgio de. Teoria da contabilidade. 5. ed. São Paulo: Atlas, 1997.

Contabilidade gerencial. São Paulo, Atlas, 6ª Ed., 1998.

Análise de Balanços. 7. ed. São Paulo: Atlas, 1998.

JAIN, T. N. Alternative networks of accounting and decision making: a psycholinguistic analysis. Accounting Review, January, 1973.

McKAY, Melaine, ROSA, Elizabeth. The accountant's guide to professional communication, New York: The Dryden Press, 2000.

MASON, Richard O.; SWANSON, E. Burton. Measurement for management decision. Addison-Wesley series on decision support. Massachusetts: Addison-Wesley Publishing Company, 1981.

MATARAZZO, C. Dante. Análise financeira de balanços. 3. ed. São Paulo: Atlas, 1995.

MORRIS, Charles W. Fundamentos da teoria dos signos. Trad. Paulo Alcoforado e Milton José Pinto. São Paulo: Ed. da Universidade de São Paulo,1976.

NAKAGAWA, Masayuki; PRETTO, Clea Beatriz Macagnan. An interdisciplinary view of accountancy in Brazil. In: Asian-Pacific Conference on International Accounting Issues, 12th. Anais. China, 2000.

RIAHI-BELKAOUI, Ahmed. The linguistic shaping of accounting. Quorum Books, Westport, Connecticut: London, 1995.

SCHRICHEL, Wolfgang Hurt. Demonstrações financeiras. 2. ed. São Paulo: Atlas, 1999.

VERTES, Alexandre. Estrutura Análise e Interpretação de Balanços. Porto Alegre: UNISINOS, 1972. 